\title{
Hamsa
}

Journal of Judaic and Islamic Studies

5 | 2019

Muslims and Jews in Latin America

\section{Un Museo del Holocausto en Buenos Aires: Contexto de creación}

\section{Wanda Wechsler}

\section{(2) OpenEdition}

1 Journals

\section{Edición electrónica}

URL: https://journals.openedition.org/hamsa/442

DOI: 10.4000/hamsa.442

ISSN: 2183-2633

\section{Editor}

CIDEHUS - Centro Interdisciplinar de História Culturas e Sociedades da Universidade de Évora

\section{Referencia electrónica}

Wanda Wechsler, «Un Museo del Holocausto en Buenos Aires: Contexto de creación», Hamsa [En línea], 5 | 2019, Publicado el 31 marzo 2019, consultado el 16 septiembre 2021. URL: http:// journals.openedition.org/hamsa/442 ; DOI: https://doi.org/10.4000/hamsa.442

Este documento fue generado automáticamente el 16 septiembre 2021

\section{(c) (i) (9)}

Hamsa est mise à disposition selon les termes de la Licence Creative Commons Attribution - Pas d'Utilisation Commerciale - Pas de Modification 4.0 International. 


\title{
Un Museo del Holocausto en Buenos Aires: Contexto de creación
}

\author{
Wanda Wechsler
}

\section{NOTA DEL AUTOR}

El presente artículo es una selección del capítulo primero de la tesis de maestría en Investigación Histórica por la Universidad de San Andrés. La tesis fue defendida en Mayo de 2017 y se titula "¿Todo está guardado en la memoria? Los usos de la memoria del Holocausto en la Argentina a través de un museo (1993- 2013)"

\section{Introducción}

1 Durante los últimos diez años del siglo XX se intensificó la construcción de la memoria del Holocausto. Esta obra, como la de todas las memorias, estuvo franqueada por múltiples luchas de significados y formas. El Estado, junto con diversos actores, se encontró en un escenario complejo donde negociar.

2 En los años setenta las resonancias de la memoria del Holocausto penetraron en los orígenes mismos de la última dictadura militar argentina. Desde 1976 fueron visibles y públicas las voces que desde el exterior del país denunciaban al régimen por perpetrar un genocidio. Tal como señala Emmanuel Kahan (2014), dicha denuncia antecedió con creces el reclamo de personas detenidas desaparecidas interpuesto por los organismos de derechos humanos.

3 Desde el advenimiento de la democracia en 1983, el gobierno de Ricardo Alfonsín realizó algunos intercambios y consagró reconocimientos a la comunidad judía tales como la incorporación de los judíos desaparecidos al "Nunca Más" o la sanción de la ley 23.592 (3 de agosto de 1988), conocida también como Ley Antidiscriminatoria, cuyo ideólogo fue el abogado penalista Bernardo Beiderman. Sin embargo, en un período posterior, durante los dos mandatos de Carlos Saúl Menem en la presidencia 
(1989-1999, reelecto en 1995), se gestó con mayor fuerza el nacimiento de instituciones dedicadas a la memoria del Holocausto, instituciones que mantuvieron asiduas relaciones, negociaciones e intercambios con el Estado.

4 En el periodo presidencial de Menem, el vínculo con la comunidad judía fue tenso. Por un lado, la sociedad sufrió dos atentados terroristas a instituciones judías: a la Embajada de Israel, primero, y a la Asociación Mutual Israelita Argentina, después. Por otro lado, aunque parcialmente influenciado por estos hechos, el gobierno activó de diferentes formas un conjunto de acciones vinculadas a las instituciones judías, entre las cuales solamente algunas estuvieron relacionadas con la memoria del Holocausto. Aún más, durante aquellos años se desarrollaron pocos canales institucionalizados, oficiales y legítimos, que reconocieron los actos de violencia de Estado y represión, tanto en lo que atañe a la memoria de la última dictadura militar de 1976-1983 como a la del Holocausto.

5 Para los familiares de detenidos desaparecidos de la última dictadura militar en Argentina la lucha fue áspera y difícil. Las disputas por "Verdad, Memoria y Justicia" y por la voz de los silenciados se desarrollaron mayoritariamente en la arena societal con acompañamiento de algunos actores políticos. Los organismos de derechos humanos vinculados a los crímenes de la última dictadura crecieron y obtuvieron visibilidad pública. Asimismo, el litigio contra las juntas militares en los años ochenta había sido considerado un hecho de justicia por parte de las víctimas y familiares del Terrorismo de Estado, aunque las denominadas "leyes de impunidad"- entre ellas la Ley de Punto Final y de Obediencia Debida ${ }^{2}$ del gobierno de Alfonsín, provocaron indignación e incentivaron aún más la construcción del movimiento de derechos humanos.

El comienzo de la presidencia de Menem estuvo signado por la concesión de indultos a civiles y militares que había cometido delitos durante la dictadura militar. Una serie de diez decretos sancionados entre 1989 y 1990 indultó a más de mil doscientas personas y se sumó a las "leyes de impunidad" ya mencionadas, aunque con la diferencia de que estas últimas fueron votadas en el Congreso. Las organizaciones de derechos humanos preexistentes a este gobierno, "Madres de Plaza de Mayo", "Abuelas de Plaza de Mayo", "CELS", como las nuevas- "H.I.J.O.S"3-, debieron apoyarse más en la autogestión u organización y perseverar en su lucha en un medio carente de canales generados por el Poder Ejecutivo más con ciertos sostenes dispuestos por los poderes Legislativo y Judicial.

7 Durante los años analizados el movimiento de derechos humanos, sin ausencia de debates internos y líneas en puja, no cesó de crecer y ganar visibilidad pública, acompañados cada vez más por una mayor parte de la sociedad. El año 1996 fue el $20^{\circ}$ aniversario del comienzo de la última dictadura militar y el 24 de marzo de ese año alrededor de cien mil personas marcharon del Congreso a Plaza de Mayo para conmemorarlo. La movilización, convocada por la Comisión por la Memoria, la Verdad y la Justicia, fue la clara demostración pública de que los crímenes del Terrorismo de Estado no habían quedado en el olvido. La marcha indujo el inicio del juicio español a cargo Baltasar Garzón y motorizó investigaciones basadas en el derecho a la verdad y vinculadas con el robo de niños ${ }^{4}$. En concreto la visualización de estos organismos a nivel público se acrecentó especialmente a finales de la década de los años noventa.

8 Un proceso similar se vivenció entre las instituciones y organismos ligados a la memoria del Holocausto. De forma creciente se estableció una memoria colectiva sobre estos dos sucesos históricos (Terrorismo de Estado y Holocausto), definida como un 
movimiento dual de recepción y transmisión, que continúa alternativamente hacia el futuro.

9 Ahora bien, para su consolidación fue necesaria, primariamente, la existencia de actores y de acciones específicas tales como homenajes, conmemoraciones, ritos, escritos, publicaciones, documentos y lugares físicos que, a continuación, pautaran la forma y el contenido de lo recordable. Como afirmó Guglielmucci, "para que podamos hablar de 'memoria colectiva' no sólo tiene que haber experiencias vividas en común, es preciso que se dé un proceso de homogeneización y, cabría agregar, de homogeneización de la diversidad de los recuerdos personales, pues la memoria colectiva no existe en sí, sino que ella es parte de un proceso social surcado por relaciones de poder"5.

10 Tanto en el caso de la memoria del Terrorismo de Estado como del Holocausto, durante los años noventa se desplegaron diferentes mecanismos y espacios que actuaron como modelos para ambos, lo que generó una "retroalimentación memorial". Estos procesos memoriales presentaron características comunes que enriquecieron sus luchas y fue en esa misma década que ganaron protagonismo.

11 Un primer rasgo compartido consistió en centrar el sistema de representaciones en el testigo, sobreviviente de campos de concentración o exterminio, de ghettos, de torturas. Para ambos este sistema se tornó clave en las formas de construir y transmitir las memorias. Los sobrevivientes tanto a los nazis en Europa como a los militares en Latinoamérica aparecen en el centro de la memoria pública compartida, como representantes de la verdad.

Otro aspecto se relaciona con la existencia de los campos de concentración o centros clandestinos y espacios de tortura, denigración y deshumanización. Tanto en el Holocausto como en la última dictadura, con sus claras diferencias, los Estados implementaron un proceso de planificación del terror, de asesinatos y de la desaparición de los cuerpos.

Finalmente, junto a los puntos anteriores, ambos procesos y sus representaciones alertaron sobre las formas posibles de terror político y odio a "otro".

En este marco brevemente esbozado, el presente trabajo indaga el proceso social de producción e implementación, construcción y materialización de la memoria del Holocausto en Argentina. Con este fin se analiza un caso específico: la formación del Museo del Holocausto como vehículo de la memoria. Este proceso dependió del nacimiento y proliferación de varias organizaciones no estatales, pero también del apoyo estatal en varios sentidos.

La vinculación entre el Museo y los diferentes gobiernos fue inconstante, con momentos de mayor o menor acercamiento. Las acciones y declaraciones del ámbito privado estuvieron, en su mayoría, condicionadas o actuaron como respuesta a las diferentes políticas estatales. Fue la relación entre los fundadores del Museo del Holocausto y algunos agentes estatales ${ }^{6}$ lo que movilizó y permitió el proceso de expansión de la memoria. Algunos funcionarios facilitaron espacios, subsidios, fomentaron monumentos, entre otras cosas.

16 La memoria en torno al Holocausto formó parte de un proceso que comenzó a darse a nivel global y se ubicó paulatinamente en la Argentina a fines de los años ochenta. Esa memoria se negoció en el seno de las creencias, los valores, los rituales y las instituciones del cuerpo social. Se configuró poco a poco en los llamados "espacios 
públicos de la memoria" como museos, memoriales, monumentos e instituciones dedicadas a la transmisión y educación.

La mayoría de los organismos vinculados a la memoria del Holocausto en Argentina nació en un mismo período, aunque algunas instituciones como Sherit Hapleitá ${ }^{7}$ son preexistentes. Entre estas instituciones se encuentran el Centro Simón Wiesenthal, la Fundación Memoria del Holocausto, Generaciones de la Shoá y el Centro Ana Frank.

El Museo del Holocausto en Argentina fue creado como parte de la obsesión memorialista o globalización de la memoria, manifiesta a nivel internacional. Esta institución es representativa de la construcción de la memoria del Holocausto por haber sido el primer proyecto museístico de Latinoamérica. Su ejecución implicó la planificación de múltiples estrategias dedicadas a la memoria: la creación de un archivo, una biblioteca, una muestra, espacios de capacitación, entre otras.

\section{El menemismo: período de apertura y atentados}

El fenómeno de la multiplicación de espacios vinculados a la memoria del Holocausto en Argentina se comprende a partir de algunos hechos sucedidos durante la última década del siglo XX. Desde la primera presidencia de Menem diferentes acciones gubernamentales explican el auge y el posicionamiento alcanzado por tal fenómeno, impulsado al mismo tiempo por factores endógenos y exógenos. Sin dejar de advertir la importancia de este segundo grupo, se presenta a continuación el derrotero de los principales sucesos nacionales.

En el año 1992 el Poder Ejecutivo abrió por medio del decreto 232 los archivos secretos depositarios de documentación sobre el ingreso, la presencia, la residencia y la salida de decenas de criminales nazis en territorio argentino. De acuerdo con el decreto, a los treinta días de la fecha de sanción del mismo, los archivos podían ser consultados por cualquier ciudadano o investigador.

21 Previamente, en el mes de noviembre de 1991 Carlos Menem había viajado a Estados Unidos, país con el cual se mantenían relaciones cercanas. En esos años, sobre todo, se intentó "hacer buena letra"8. Precisamente, fue en el marco de esta que visita el titular del Congreso Judío Mundial ${ }^{9}$ Edgar Bronfman le solicitó en un encuentro que realizara la apertura de los archivos ${ }^{10}$.

22 Sin embargo, la apertura de estos archivos no significó grandes cambios. Según Abraham Zylberman, historiador integrante del Museo a través de la Comisión de Cultura y Educación:

"Los archivos resultaron ser recortes de diarios, porque la gran parte de los materiales había desaparecido en algún momento, yo supongo que en la dictadura militar. Los recortes que había, no eran secretos. Esa apertura eran recortes de diario, no agregaba absolutamente nada. Fue más una cosa de propaganda" ${ }^{11}$.

23 Asimismo, durante esos años la Cancillería argentina auspició dos eventos académicos internacionales, uno sobre el tema del genocidio y otro sobre discriminación y racismo. Las ponencias de estos eventos fueron publicadas en dos volúmenes ${ }^{12}$. El canciller Di Tella desarrolló una intervención en estos eventos académicos, en la cual hizo referencia a la apertura de los archivos nazis. Así afirmó:

“... Como ustedes saben, hace alrededor de un año el gobierno decidió abrir los llamados archivos nazis. Se decidió hacerlo porque la Argentina tiene una deuda con algo bochornoso que ocurrió en nuestro pasado. Lo ocurrido no va a cambiar 
porque lo investiguemos y lo conozcamos mejor, pero existen varios motivos por los que la transparencia sobre el tema es para nosotros un imperativo (...) Lo hacemos, en primer lugar, porque nosotros tenemos que pedir disculpas a la comunidad judía en la Argentina y en el mundo, y a todos los amantes de los derechos humanos, por lo que ocurrió en nuestro territorio patrio, donde con la indiferencia a veces y con la complicidad directa otras veces, agravamos la situación generada por la demencia racista de los nazis. También lo hacemos porque tenemos una deuda histórica con el Estado de Israel. Nuestras relaciones con Israel no fueron buenas en el pasado, primero porque tuvimos gobiernos autoritarios que padecían de una suave antipatía tanto frente al Estado de Israel como frente a la comunidad judía. Luego, cuando se produjo el cambio hacia la democracia, la Argentina siguió siendo esquiva a dar un apoyo explícito hacia Israel debido al "tercermundismo" adoptado por nuestro gobierno en ese momento. Ahora, finalmente, nos hemos reencontrado con Israel de una manera profunda y completa, y la apertura de los archivos es un símbolo de esta feliz evolución. Finalmente, abrimos los archivos porque deseamos contribuir al cambio cultural del país. Según entiendo por lo que conversé con los organizadores, ése es también el espíritu que anima a este simposio. La apertura de los archivos y esta misma conferencia que hoy inauguramos nos conviene a los argentinos más que a nadie, por cuanto es un signo de que comenzamos a asumir la responsabilidad del pasado y a democratizar nuestra cultura. Los países que no asumen su pasado tienen una tendencia a incurrir nuevamente en errores y horrores parecidos. Salir de este círculo vicioso es una prioridad de nuestra gestión de gobierno. Es por esto que no solamente hemos abierto los archivos correspondientes a ese capítulo de nuestro pasado, sino que también hemos creado una Comisión de Archivos, presidida por el Embajador Andrés Cisneros y constituida por nuestros principales expertos en archivística. Su misión es reglamentar y organizar nuestros archivos para ponerlos a la altura de las técnicas más actualizadas."

En este discurso se hizo presente la voluntad del gobierno de Menem de resarcirse, pedir perdón y volver a establecer las relaciones con Israel, como parte de su estrategia de consolidar el vínculo con Estados Unidos y con la comunidad judía del país. Las palabras pronunciadas por Di Tella dejaban entrever, además, una deuda del Estado Argentino con la comunidad judía creada durante la dictadura militar y la persecución.

Poco después, en el año 1996, salieron al dominio público los libros de asientos del Banco Central de la República Argentina, que contienen datos sobre transacciones en oro nazi y otros movimientos financieros de la Argentina durante el período comprendido entre los años 1933 y 1955, entre otros. El centro Simón Wiesenthal ${ }^{13}$ fue uno de los principales comprometidos en reclamar al gobierno argentino la apertura de estos archivos, con el objetivo de inspeccionar sus depósitos y transferencias, y demostrar el ingreso de oro nazi al país. En una entrevista publicada en el diario Clarín ${ }^{14}$ Shimon Samuels, vicepresidente de la organización dedicada a la "caza de criminales nazis" en todo el mundo, declaró que solicitaban "la revisión de todas las transacciones bancarias y transferencias arribadas y salidas del Banco Central de la República desde Alemania, Suiza, Suecia, Portugal y España durante y después de la Segunda Guerra Mundial". A su vez, explicó que la intención era determinar no sólo el camino del oro saqueado, sino también probar si había llegado dinero de las víctimas del Holocausto a la Argentina.

Finalmente, otro suceso relevante del gobierno de Menem consistió en la creación de la Comisión para el Esclarecimiento de las Actividades del Nazismo en la Argentina (CEANA), mediante el Decreto 390, promulgado en mayo de 1997. La labor de la CEANA ha sido y es aún objeto de defensas y críticas. Mientras las primeras destacaron su labor 
de "esclarecimiento", las últimas afirmaron, en cambio, un "encubrimiento" de dichas actividades, que habrían contado además con la complicidad de los funcionarios del gobierno. La apertura de los archivos movilizó y puso en un primer plano el vínculo de Argentina con el nazismo. En este sentido, provocó diferentes movimientos: Sergio Widder, director del Centro Simón Wiesenthal Argentina, una de las primeras instituciones vinculadas con la memoria del nazismo, afirmó que la apertura de los archivos fue una de las razones para el nacimiento de esta organización, que dedica su trabajo a "la caza de nazis" en el país, recopilando información ${ }^{15}$. Como podemos advertir, en este caso los actos del gobierno movilizaron la creación de un Centro de investigaciones vinculados con el Holocausto.

Estas acciones impulsadas desde el gobierno, que implicaron la apertura de archivos secretos, el auspicio de eventos académicos, la puesta al dominio público de ciertos archivos del Banco Central y el decreto de esclarecimiento, forman parte de un contexto que favoreció la aparición de instituciones relacionadas con la memoria del Holocausto. No obstante, hubo otros sucesos que si bien no dependieron del accionar del gobierno, lo propiciaron de manera indirecta.

Dos atentados movilizaron al país durante la década del noventa. El 17 de marzo de 1992 un atentado voló la embajada de Israel en Buenos Aires y causó 22 muertos. A menos de dos años transcurridos, otro atentado devastó la AMIA, Asociación Mutual Israelita Argentina, espacio central e histórico de la comunidad, fundada a fines del siglo XIX. El 18 de julio de 1994 una bomba destruyó el histórico edificio de la institución y causó 85 muertes y cientos de heridos y fue calificado como el ataque antijudío más grande desde la Segunda Guerra Mundial. Ambos atentados fueron un duro golpe para la comunidad judía argentina y precipitaron un debate sobre la condición de víctimas de los judíos en el espacio público en el país. Este debate conllevó un discurso de homologación de la experiencia con el Holocausto ${ }^{16}$. También aceleró la aparición de espacios para rememorar el genocidio judío como, por ejemplo, la Fundación Memoria del Holocausto. Si bien desde 1989 existía ya un grupo que venía planificando y realizando acciones vinculadas a la memoria, fue luego de los atentados que ellas concretaron su institucionalización y crecimiento.

Frente a estos sucesos de violencia, la colectividad judía se vio fuertemente amenazada. Esto generó cierto temor a la desaparición, a la repetición del horror, y reavivó el trauma vinculado con el Holocausto. Estos atentados revivieron viejas heridas sin cicatrizar. Y aunque fueron sucesos totalmente diferentes al Holocausto, ambos hechos históricos compartieron un aspecto clave: afectaron directamente a la comunidad judía y revivieron un hecho sucedido cuarenta años atrás.

30 En ese contexto se hizo presente una preocupación por rescatar y resaltar el pasado en el presente. La constitución, la institucionalización, el reconocimiento y la fortaleza de las memorias y de las identidades se alimentan mutuamente ${ }^{17}$. En la memoria colectiva se presentan diversos tiempos: períodos calmos y otros de crisis. Los años de los atentados significaron una etapa de crisis para la comunidad judía, insegura frente a una amenaza externa. Estos períodos conducen muchas veces a una reinterpretación de la memoria grupal y a un cuestionamiento de la identidad. Las crisis son sucedidas por desequilibrios en la identidad colectiva y de la memoria, momentos en que "puede haber una vuelta reflexiva sobre el pasado, reinterpretaciones y revisionismos, que siempre implican también cuestionar y redefinir la propia identidad grupal"18. 
31 Frente a una tímida respuesta del gobierno de cara a los hechos ocurridos, diferentes organizaciones surgieron desde los sobrevivientes y familiares. Algunos ejemplos son el Centro Wiesenthal y la Fundación Museo del Holocausto. Los atentados habían reforzado la necesidad de instalar con mayor presencia la memoria referida al Holocausto, expandirla hacia ámbitos no comunitarios.

También los atentados modificaron en varios aspectos a los espacios de la comunidad judía. Por ejemplo, las sedes de colegios, templos, instituciones, museos, colocaron en sus frentes pilotes de cemento para la seguridad y se incrementaron los controles para el ingreso. Los espacios de la comunidad quedaron cerrados, marcados y aislados en plena ciudad. Los pilotes de cemento pasaron a identificar sinagogas, clubes, escuelas, entidades de asistencia y culturales judías ${ }^{19}$.

\section{El Museo del Holocausto: creación e historia}

Varios actores intervinieron en el trabajo de construcción y formalización del Museo del Holocausto de Buenos Aires. Con diferentes trayectorias y en diferentes tiempos, trabajaron para legitimar una memoria. En el caso de los actores no estatales, los promotores del proyecto museo, pueden ser denominados "emprendedores". Este concepto, de acuerdo con Jelin, no tiene por qué estar asociado con el lucro económico privado y se diferencia del rol de empresario ${ }^{20}$. Son emprendedores de carácter social o colectivo y se involucran personalmente en su proyecto, pero comprometiendo a otros, generando participación y realizando una tarea colectiva. El emprendedor trabaja en grupo y el trabajo puede implicar jerarquías sociales, mecanismos de control, espacios de poder y división del trabajo bajo el mando de estos emprendedores. En su rol, y para llevar adelante sus proyectos, emplean gente y pagan sueldos, además de tener voluntarios.

En el caso estudiado quienes movilizaron la causa por la memoria son principalmente descendientes de sobrevivientes, denominados "Segunda generación". Su vínculo con la temática estuvo fuertemente marcado por una historia familiar personal, como suele ocurrir por lo menos en un comienzo. El protagonismo privilegiado fue de las generaciones posteriores a las víctimas y también de algunas de ellas. El desafío de este grupo consistió tanto en instalar y expandir la temática entre la sociedad como posibilitar también su reproducción por los no familiares. Los fundadores del Museo, interesados en la causa memorial forman parte de la colectividad judía. Aparece aquí un segundo desafío: la expansión de la memoria a sectores externos a la colectividad.

Los fundadores del Museo del Holocausto realizaron un lento y largo trabajo que llevó a la instalación de la temática y a la legitimación de su posición a través de vínculos con ese pasado, afirmando su continuidad. Para instalar el tema vinculado con la memoria como una cuestión pública, fue menester un proceso que requirió esfuerzos y perseverancia. Constó de diferentes instancias: primero, la conformación de un núcleo de trabajo y formación; luego, la búsqueda por ganar visibilidad pública y legitimar una versión de esos sucesos, a través de actividades y espacios. En este período el grupo fundador del Museo tomó la iniciativa de "salir" de la comunidad y conseguir un espacio propio.

La Fundación Memoria del Holocausto (FMH) firmó su escritura y acta fundacional el 8 de mayo del año 1994. Sin embargo, los orígenes de esta organización se sitúan en un 
tiempo anterior. En el año 1987 un grupo de amigos y conocidos, conectados de diferentes maneras con el Holocausto, se reunió en la casa de uno de ellos. Allí, según el recuerdo de Susana Rochwerger, el profesor Abraham Huberman dijo “...en la Argentina, la Shoá se recuerda un día, no se estudia, no se analiza...”21. A partir de ese encuentro entre familiares de víctimas, la ingeniera Noemí Kaplan de Richter emprendió la idea de crear un centro educativo especializado en el Holocausto. El 6 de junio de 1988 tuvo lugar el acto fundacional del Instituto Argentino para estudios del Holocausto (IAEH) en un auditorio cedido por la AMIA, bajo el lema "¿Por qué recordar?". Ese acto contó con la colaboración del Secretario de Cultura de AMIA, el Ingeniero David Filc y el Embajador de Israel Ephraim Tari. La exposición en el acto estuvo a cargo de Abraham Huberman por parte del IAEH y el aporte de Yosi Goldstein, de la Universidad Hebrea de Jerusalén, Moises Kijak, médico psiquiatra, Irene Dab, sobreviviente y psicóloga, y Daniel Fainstein, decano de Estudios del Seminario Rabínico Latinoamericano.

Abraham Huberman era licenciado de la Universidad Hebrea de Jerusalén en Historia judía y universal y profesor de Historia judía, especialista en la temática del Holocausto y fue quién organizó las tareas de trabajo a encarar. Entre ellas fue central la compilación de testimonios de sobrevivientes que vivían en Argentina, para la cual se organizó un departamento de testimonios, con un equipo de voluntarios. Este fue el primer trabajo de recopilación de testimonios de sobrevivientes del Holocausto realizado en el país y formó parte de un movimiento global de registro de testimonios.

El primer testimonio relevado fue el de la familia Klich. Se comenzó a tomar testimonios "a mano", luego con un grabador y finalmente, con ayuda de la Universidad de Yale, se firmó un convenio para poder filmar, en contacto con el Video Archivo Fortunoff ${ }^{22}$. Siendo Argentina un país con una gran cantidad de sobrevivientes del Holocausto, pareció un proyecto loable. Para esto se elaboró un documento, el "Memorándum informativo acerca del Proyecto de creación del Centro de documentación y archivo de testimonios", que afirmó la adhesión al proyecto de algunas instituciones judías como el JOINT Argentina, la Sociedad Hebraica Argentina, Escuela ORT y Asociación Marcha por la Vida. Estas instituciones se comprometían a proveer infraestructura tecnológica, horas voluntarias, horas profesionales y difusión. También este documento manifestó la necesidad del nombramiento de un director técnico y dos asistentes rentados, siendo todos los demás voluntarios. El proyecto hizo hincapié en la consustanciación de los profesionales y voluntarios con los principios éticos y morales del memorándum: contribuir a derribar las barreras del odio y prejuicio que la ignorancia, a veces involuntaria, genera ${ }^{23}$.

39 Este primer espacio organizó diversos tipos de actividades para poner en funcionamiento este grupo: encuentros para hijos de sobrevivientes, programaciones radiales por Radio Municipal, proyección de películas, talleres para niños, jornadas sobre discriminación, actos conmemorativos y un seminario para periodistas y comunicadores que desconocían la temática. Rochwerger, una de las primeras integrantes, aseguró que debieron superar el escepticismo, la indiferencia y el poco eco en la dirigencia comunitaria ${ }^{24}$, aunque como se mostró en el memorándum, gran parte de ella lo apoyó.

40 En el año 1993, después del atentado a la Embajada de Israel y con algunos años de trayectoria, este grupo convocó más personas y el IAEH se convirtió en una Fundación (FMH). Entre los primeros integrantes además de profesionales había sobrevivientes e 
hijos de sobrevivientes: Mónica Davidovich, Susana Rochwerger, Gilbert Lewi, Jaime Machabanski, Abraham Huberman, Jack Fuchs, Alfredo Berflein, Sima Milmaniene, Abraham Zylberman, León Grzmot, Eugenia Unger.

41 Al convertirse en una Fundación este grupo pasó a estar dotado de personalidad jurídica privada, sin fines de lucro y esto implicó la condición de contar con un patrimonio. Convertirse en fundación también involucró una previa autorización y reconocimiento por parte del Estado para funcionar, hecho que favoreció su visibilización pública.

La Fundación no surgió con los objetivos de materializarse en un museo sino como un espacio para la transmisión y la memoria con un centro de documentación. Sin tener un espacio físico propio comenzó a funcionar en unas pequeñas oficinas de la calle Rivadavia, cedida por FACCMA ${ }^{25}$ y los estatutos de la Fundación, gestionados por los escribanos Blacher, afirmaron:

"Los integrantes de la 'Fundación Memoria del Holocausto' tomamos la responsabilidad de la creación de un espacio que dé respuesta civilizada a la ignorancia casi total o al conocimiento confuso y poco riguroso sobre la SHOÁ en nuestra República Argentina. Este es nuestro desafío...y lo cumpliremos".

Fuertemente anclado en aquel presente, enmarcado en la movilización posterior a los atentados, aparecieron allí consignas contra la discriminación, la xenofobia, el prejuicio y el odio. Apareció una consigna a resaltar: “iPor la verdad!”. Esta fue también eje de movilización en las organizaciones de derechos humanos sobre la memoria del Terrorismo de Estado.

En abril de 1994 en el acta fundacional se determinó que esta organización sin fines de lucro tenía por objeto "promover todo tipo de actividad cultural, técnica, científica, de investigación que tenga por finalidad la promoción y/o difusión de la memoria del holocausto en Argentina" ${ }^{26}$. Para estos objetivos pretendieron:

“...a) programar y realizar planes de estudio y actividades relativas al análisis, esclarecimiento y evaluación del holocausto, b) proveer la difusión, por todos los medios, de las causas que indujeron al desarrollo del HOLOCAUSTO, procurando impedir su repetición en el futuro, c) educar e instruir a las generaciones del futuro, esclareciéndolas debidamente para valorar el sacrificio y calidad del pueblo judío,

d) Promover la creación de Centros Formativos y de Estudios relativos al tema y e) Decidir todo otro medio lícito de expresión pública y privada relacionado con los fines de la entidad".

De esta manera los fundadores presentaron los objetivos basados en tres líneas: esclarecer el Holocausto, promover y difundir su memoria por diferentes medios y educar a las próximas generaciones, valorando el sacrificio y calidad del pueblo judío.

¿Quiénes fueron estos primeros fundadores, estos emprendedores del proyecto de Memoria? Sobrevivientes del Holocausto y familiares buscaron un proyecto unificador, de la mano de un grupo de personas dedicadas a los derechos humanos. Entre ellos se encontraban Abraham Huberman, Gilbert Lewi, Susana Rochwerger, Jaime Kattan, Mónica Dawidowicz, Eugenia Unger, León Gzmot, Sergio Miodownik entre otros. Para trabajar y crecer hacia afuera de la comunidad judía, comenzaron con la búsqueda de un espacio propio. Con ambición y gran entusiasmo, Gilbert Lewi fue el principal emprendedor en términos monetarios y motivacionales. Él movilizó sus energías en función de la causa memorial y pedagógica, buscando reconocimiento social y legitimación de la temática en el país. 

grupo se reunía en confiterías cercanas al Hospital Otamendi (Azcuénaga y Córdoba) debido a una situación grave que sufría la madre de Lewi. Allí se planteó la necesidad de conseguir un espacio propio. En ese contexto fue el diputado del Chaco, Claudio Mendoza, quien se acercó a Lewi y a este primer grupo para promover la participación del mismo en la creación de un monumento. Según Jinich, Mendoza se interesaba por los derechos humanos y había tenido contacto ya con Lewi en otras ocasiones. Aquí intervino un actor estatal con una fuerte dedicación a la temática.

Figura 1 - Monumento a la Humanidad: «Monumento a la Humanidad, Resistencia, Chaco, Argentina» en Claudia Aranovich. Exhibiciones Individuales. Disponible en http:// www.claudiaaranovich.com.ar/imagenes/chaco.jpg (29-11-2018).

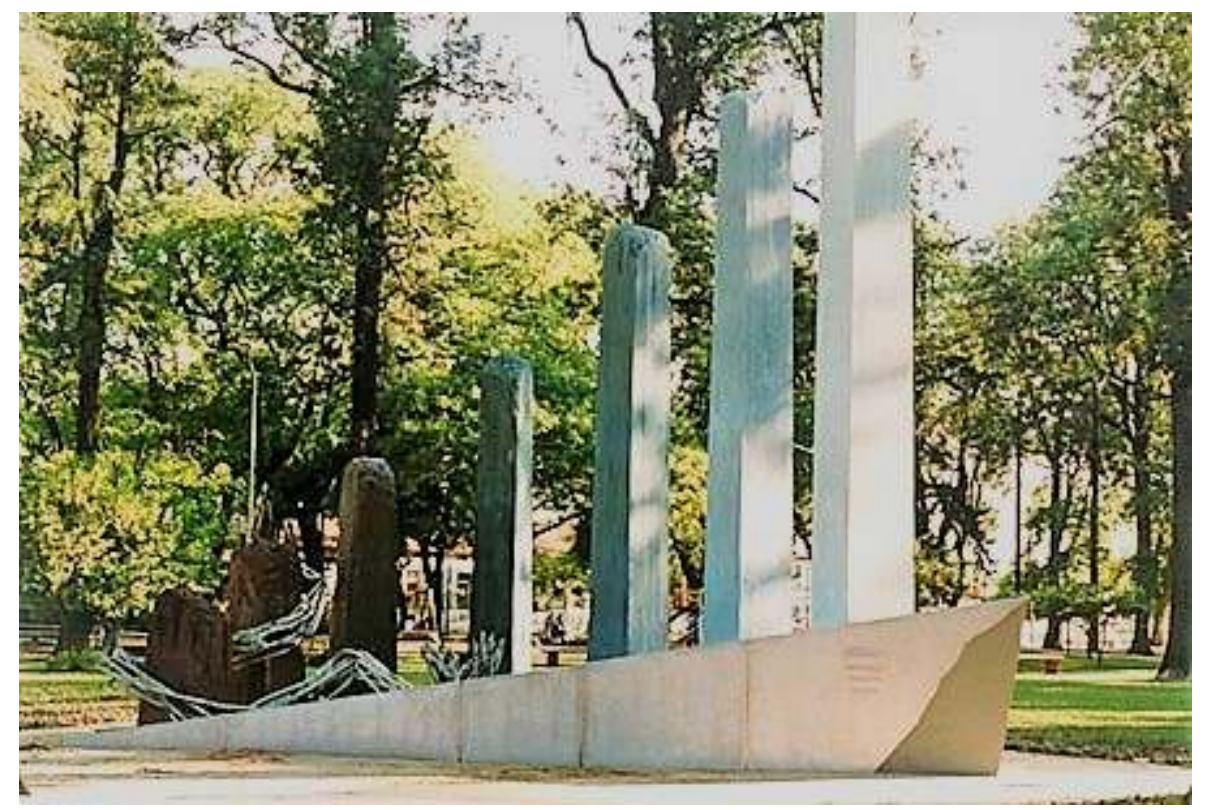

Mendoza fue uno de los movilizadores de las causas de derechos humanos durante la década de los noventa, vinculado también con Abuelas de Plaza de Mayo. Diputado nacional y provincial por el Chaco del Partido Justicialista, movilizó diferentes actividades, monumentos y espacios por la memoria. Su interés en la memoria del Holocausto lo convirtió en el primer no judío ni pedagogo en viajar a Israel a estudiar en Yad Vashem, el centro de estudios sobre el Holocausto situado en Jerusalén.

En el año 1994, Mendoza se comunicó con Lewi para realizar un monumento sobre el Holocausto en la Plaza de las estatuas en el centro de Resistencia, Provincia de Chaco. Este fue el primer monumento sobre el tema construido en un espacio público. Llamado "Monumento a la Humanidad", fue realizado por la escultora ${ }^{27}$ Claudia Aranovich, junto con los arquitectos Ben Waisman y Marcelo Senra y se erigió en la Plaza 9 de Julio.

La inauguración del primer monumento en Chaco fue una oportunidad para que representantes de la FMH, como Graciela Jinich y Eugenia Unger, sobreviviente del Holocausto, difundieran el proyecto a través de unas carpetas tituladas "Proyecto". Esta ocasión vinculó a la FMH con el Ministro del Interior Carlos Corach. Quienes también se encontraban en esa inauguración eran Estela de Carlotto y Rosa Tarlovsky de Roisinblit, presidenta y vice de Abuelas de Plaza de Mayo, León Grzmot (sobreviviente de los campos de concentración), Graciela Fernández Meijide, diputada por el Frente Grande y activista por los derechos humanos y ministros del gobierno de Menem, como Carlos 
Corach y Jorge Alberto Rodríguez (Ministro de Educación). Esta fue una de las primeras ocasione ${ }^{28}$ en las que aparecieron en la escena pública representantes de la memoria del Terrorismo de Estado y del Holocausto convocados por "La Memoria"29.

51 Luego de este acto los integrantes de la FMH fueron convocados a la Casa Rosada por el Ministro del Interior Carlos Corach para conversar sobre la donación de un espacio físico de trabajo. Según Jinich fueron ella y la sobreviviente Eugenia Unger junto con Lewi quienes participaron de la reunión ${ }^{30}$.

El Estado, lejos de aparecer como un gran aparato despersonalizado y monolítico, se presentó a través de los lazos y relaciones personales preexistentes. La inauguración del monumento y la convocatoria del ministro se llevaron a cabo en 1994 y fueron posteriores al atentado de la AMIA. Según la opinión de Jinich, "la convocatoria fue después de los dos atentados y tuvo que ver, totalmente, le convino a todas las partes eh, no sólo al gobierno, le convino también a la fundación" ${ }^{31}$.

Corach no sólo promovió la entrega de un edificio, sino también aportó económicamente durante varios años para el Museo ${ }^{32}$. A partir de ese encuentro la FMH comenzó con la búsqueda de un espacio físico visitando los edificios ofrecidos por el gobierno nacional.

54 A fines del año 1994 la Inspección General de Justicia emitió la resolución por la cual se autorizaba el funcionamiento de la FMH. Durante el verano de 1994 a 1995, Jinich junto con un arquitecto de la Sociedad de Arquitectos recorrieron entre cuarenta y cincuenta propiedades del Estado. Si bien fue acompañado por el Ministro del Interior Carlos Corach, este proceso estuvo a cargo de Bienes del Estado dependiente del Ministerio de Economía. Estos espacios estatales fueron recorridos y aconsejados por quien era entonces el director del Palais de Glace Julio Sapollnik. El primer espacio elegido por la fundación fue el denominado "La cochera presidencial", ubicado en la calle Leandro $\mathrm{N}$. Alem al 800, el cual contenía los autos presidenciales para ser visitados por el público. Sin embargo, un hecho trágico ocurrido el mismo día de la firma obstaculizó su entrega ${ }^{33}$. La FMH se vio obligada a cambiar la elección. Finalmente, se concretó la cesión del edificio ubicado en la calle Montevideo $919^{34}$, donde se erigió el Museo años después.

Con la cesión del edificio comenzó el desafío de la creación de un espacio de memoria. Para esto la FMH emprendió su trabajo con la Sociedad de Arquitectos, junto con los arquitectos Aisenson, Keselman, Aslan y Novoa, y se organizó una cena recaudatoria en el Hotel Alvear a fines del año $1995^{35}$. En aquel entonces el discurso central fue del sobreviviente y Premio Nobel de la Paz Elie Wiesel, quien ya había visitado el país anteriormente ${ }^{36}$.

56 El acto de entrega del edificio situado en Montevideo 919 por parte del Estado Nacional fue realizado en el aniversario de los cincuenta años de la finalización de la Segunda Guerra Mundial, el 8 de mayo de 1995 y coincidió con el cierre de campaña para la reelección presidencial de Carlos Saúl Menem. En esta ocasión el doctor Lewi, presidente de FMH resaltó en su mensaje, por un lado, el vínculo de la Fundación con el Estado: "Este acto de aporte del Estado Nacional (...) marca un hito histórico en la posición asumida, por nuestro gobierno frente a las actividades de la sociedad civil en materia de lucha antidiscriminatoria". Por otro lado, también destacó la relación entre el nazismo y los sucesos argentinos de la dictadura y los atentados:

"Una matanza masiva, como la que ocurrió en menos proporción en nuestro país

durante la dictadura militar, o el doble atentado contra la comunidad judía, que aún 
hoy nos mantiene atónitos y sin saber por qué realmente sucedió, y quiénes son los culpables, tiene que ser recuperado desde la memoria para que nunca más vuelva a suceder. Si así lo comprendemos, comprendemos que somos todos sobrevivientes, judíos y no judíos, porque esta perspectiva del nunca más, nos ubica claramente en el camino de la vida"

(FMH. (Mayo de 1995). Editorial. Nuestra Memoria, 3, 2, 3). concedió por primera vez un edificio propiedad del Estado para un fin vinculado a la memoria del Holocausto. Cincuenta años después del fin de la Segunda Guerra Mundial y en un territorio que no participó activamente en ella, se decidió otorgar un espacio físico para sostener una memoria que, a priori, no es nacional. Según Zylberman esta entrega "fue después del atentado a la Embajada de Israel o por la AMIA. La entrega del edificio fue en mayo del 94 o 95. La entrega tuvo que ver con un pretendido lavado de culpas" ${ }^{37}$.

El 24 de abril de 1995 se envió una carta a los socios y a las instituciones de la comunidad, resaltando el recorrido realizado y una necesidad de crecimiento. El objetivo de la misiva tuvo que ver con la creación de un centro de documentación y una central pedagógica sobre el Holocausto, y se realizó en la casa de Rochwerger. La misma afirmó:

"Los pueblos que no conocen su historia son pasibles de volver a vivirla. Bs. As, 24 de abril de 1995. Estimado amigo: La Fundación Memoria del Holocausto ha tomado la iniciativa de constituir un recordatorio permanente a la memoria de la SHOÁ como ya ha sido establecido en ciudades importantes del mundo.

Respondiendo a esta inquietud el Gobierno Nacional ha donado un edificio en Montevideo 919 de esta Capital para poder crear y desarrollar un museo. Su corazón será dedicado a honrar y perpetuar a las víctimas inocentes $\mathrm{y}$, a la vez, servirá de consuelo a los sobrevivientes y dará ejemplo a las jóvenes generaciones. Se creará un lugar donde el visitante pueda meditar y reflejarse en sus recónditos pensamientos, sentimientos y emociones.

Por esta razón lo convocamos para que participe del COMITÉ DE HONOR, colaborando con el desarrollo de ideas, alcances y diseño del proyecto. (...)

Contaremos con la asistencia del Sr. Ministro del Interior, Dr. Carlos Corach, quien ha manifestado su apoyo total a esta fundación.

Lo saludamos con nuestro cordial SHALOM".

En el año 1996 la Fundación realizó la mudanza a la nueva sede otorgada por el Estado con un cambio importante en la presidencia dado que el fundador Gilbert Lewi concluyó su primera gestión y tomó su lugar David Fleischer. En este cambio, la Sociedad de Arquitectos fue desplazada por la firma Dujovne - Hirsch, decano este último de la Facultad de Arquitectura y Urbanismo (UBA). Ese año comenzó la refacción y el Museo fue declarado "de interés cultural y educativo" por el Senado de la Nación, "de interés nacional" por la Cámara de Diputados y "de interés cultural" por la Secretaría de Cultura de la Nación. A la vez, aparecieron las primeras noticias en prensa relacionadas con el $\mathrm{Museo}^{38}$.

En 1997 se aprobó un Proyecto de declaración de Interés Nacional de la construcción del Museo del Holocausto en Buenos Aires. El proyecto, presentado en abril de 1996 por el diputado Darío Alessandro, fue aprobado por unanimidad por la Cámara de Diputados de la Nación el 18 de junio de 1997 e impregnó de fuerza a los fundadores. Esta iniciativa fue acompañada por los diputados Carlos "Chacho" Álvarez, Patricia Bullrich, Alfredo Bravo, Marcelo Sturbin y Ana Kessler representantes de diferentes espacios políticos. 

bien sufrió modificaciones, se sostuvo en los aspectos generales. El consejo administrativo se constituyó con un presidente, vicepresidentes, un secretario general, prosecretarios, un tesorero, vocales, vocales suplentes, un revisor de cuentas y un director ejecutivo, cargo que fue ocupado casi siempre por una mujer, salvo en una oportunidad. Además, el trabajo se dividió en comisiones, las cuales fueron variando a lo largo del tiempo. Al comienzo, las comisiones que funcionaban eran: el grupo de jóvenes, la de sobrevivientes, la de segunda generación, la de testimonio, la de edificio y la de cultura. Éstas tenían días fijos de reunión durante la semana pero con el paso del tiempo comenzaron a perecer.

Figura 2: «Museo del Holocausto. View from the street. Fotografia de viajante enviada por Cynde M (nov de 2011)» en tripadvisor. Disponible en https://www.tripadvisor.pt/Attraction_Reviewg312741- d2389910-Reviews-Museo_del_Holocausto-

Buenos_Aires_Capital_Federal_District.html\#photos;aggregationld=\&albumid=101\&filter $=7 \& f f=36846608$ (29-11-2018). «Museo del Holocausto de Buenos Aires» en Artium. DokuArt. Biblioteca y Centro de Documentación. Disponible en http://catalogo.artium.org/book/export/html/9690 (29-11-2018).

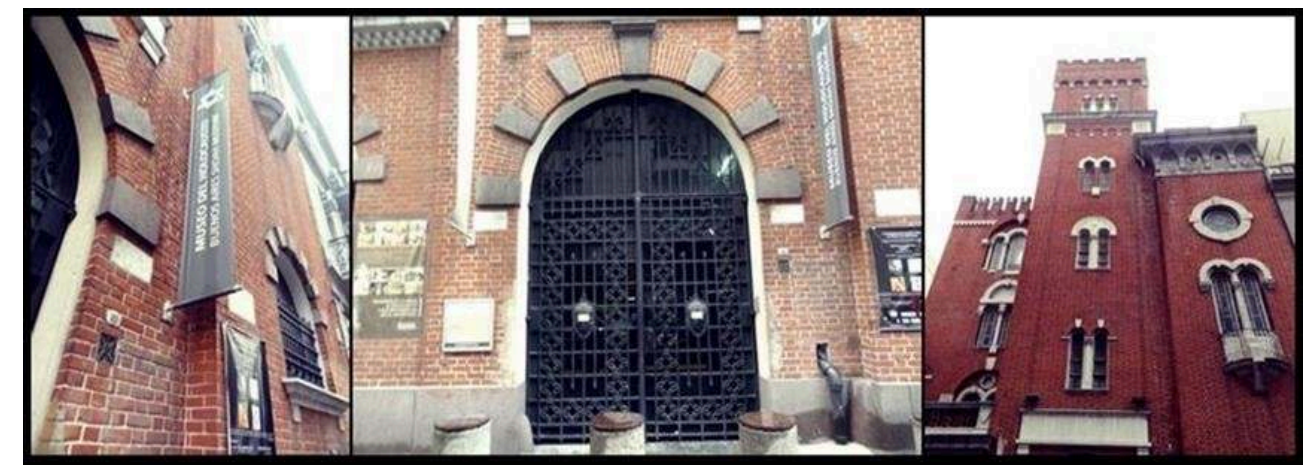

\section{Algunas consideraciones finales}

A lo largo del artículo se desarrolló el contexto de formación y la historia misma de la FMH, devenida en Museo del Holocausto - Shoá. Para ello se analizó el contexto histórico-político de aparición, situado en la última década del siglo XX, como marco que permitió comprender el nacimiento del Museo. Algunos de los sucesos ocurridos a nivel internacional y nacional dieron lugar a la aparición de la FMH en Argentina. Esta Fundación se levantó principalmente por interés de algunos sobrevivientes del Holocausto y sus familiares, la generación posterior, que se comprometió en crear un espacio dedicado a la memoria y educación en torno a lo ocurrido en la Shoá. Fueron aquí descritas la organización y actividades llevadas a cabo por la FMH.

La aparición del museo fue posible, en gran medida, por la participación de algunos actores representantes del Estado. Claudio Mendoza fue quien fomentó la creación del 
primer monumento dedicado al Holocausto y posibilitó el encuentro de algunos integrantes de la Fundación con otros políticos y luchadores por los derechos humanos; Carlos Corach, quien facilitó la donación de un espacio para construir el museo; integrantes de la Alianza, como Carlos Álvarez y Aníbal Ibarra, que declararon al museo de interés nacional.

Además de estos vínculos con actores políticos, también fue necesario construir vínculos con instituciones de la comunidad judía preexistentes. En este sentido FACCMA prestó sus instalaciones, AMIA patrocinó la refacción del museo, la DAIA, la Sociedad Hebraica Argentina, Macabi y Sherit Hapleitá coordinaron en conjunto congresos, conferencias y seminarios. A partir de algunas divisiones en el interior de la FMH también nacieron nuevas instituciones vinculadas a la memoria del Holocausto, Generaciones de la Shoá y el Centro Ana Frank.

Si bien el Museo estrechó lazos con diversas instituciones ligadas a la memoria del Holocausto e instituciones judías, mantuvo pocas relaciones con otras organizaciones de derechos humanos o vinculados al Terrorismo de Estado. Mientras el Museo se encontraba en construcción, se creó también el "Parque de la memoria", dedicado a las víctimas del Terrorismo de Estado, pero el vínculo entre estos espacios fue débil. Ambas memorias, en un período de creación, instalación pública y reconocimiento, llevaron adelante su camino por vías paralelas, que poco se cruzaron. Si bien la memoria vinculada al Terrorismo de Estado se apoyó claramente en el tropo del Holocausto, el diálogo entre instituciones memoriales fue casi inexistente. Esta circunstancia se relaciona, por una parte, con el ensimismamiento y desconfianza dentro del campo judío frente a las relaciones y usos, las comparaciones entre experiencias y el temor a abrir "demasiado" el campo de trabajo; por otra, está asociada a la forma en la cual se piensa el Holocausto desde la FMH: la unicidad. Esto implica la no comparación de los genocidios y el Holocausto como un suceso único. Para finalizar, repasamos solo algunos interrogantes que atravesaron el presente trabajo: ¿es posible articular las memorias?, ¿puede una memoria lejana iluminar a una más cercana?, ¿cómo dialoga "lo local" con "lo internacional"? Estas preguntas permanecen abiertas e invitan a una nueva investigación.

\section{BIBLIOGRAFÍA}

AVIGNOL, María Laura, “El Saqueo a las víctimas del Holocausto”, Clarín digital [en línea]. 21 de septiembre de 1996. Disponible en http://edant.clarin.com/diario/96/09/21/T-02201d.htm.

GUGLIELMUCCI, Ana, La consagración de la memoria. Una etnografía acerca de la institucionalización del recuerdo sobre los crímenes del terrorismo de Estado en la Argentina, Buenos Aires, Antropofagia, 2013.

GUREVICH, Beatriz, ESCUDÉ, Carlos, El genocidio frente a la historia y la naturaleza humana, Buenos Aires, Universidad Torcuato Di Tella, 1994.

JELÍN, Elizabeth, Los trabajos de la memoria, Madrid, Editorial Siglo XXI, 2002. 
KLICH, Ignacio, RAPOPORT, Mario, Discriminación y racismo en América Latina, Buenos Aires, Grupo Editor Latinoamericano, 1997.

WECHSLER, Wanda, ¿Todo está guardado en la memoria? Los usos de la memoria del Holocausto en la Argentina a través de un museo (1993-2013), tesis de máster en Investigación Histórica, Universidad de San Andrés, 2017.

\section{NOTAS}

2. La Ley de Punto Final estableció en el año 1986 la paralización de los procesos judiciales contra los imputados de ser autores penalmente responsables de haber cometido el delito de desaparición forzada de personas durante la dictadura de 1976-1983 en Argentina. La Ley de Obediencia Debida estableció en el año 1987 una presunción de que los delitos cometidos por los miembros de las Fuerzas Armadas cuyo grado estuviera por debajo de coronel (en tanto y en cuanto no se hubiesen apropiado de menores y/o de inmuebles de desaparecidos), durante el Terrorismo de Estado y la dictadura militar no eran punibles, por haber actuado en virtud de la denominada "obediencia debida" (concepto militar según el cual los subordinados se limitan a obedecer las órdenes emanadas de sus superiores).

3. Sobre las organizaciones: "Madres de Plaza de Mayo" es una asociación argentina formada durante la última dictadura militar argentina con el fin de recuperar con vida a los detenidos desaparecidos, inicialmente, y luego establecer quiénes fueron los responsables de los crímenes de lesa humanidad y promover su enjuiciamiento. -"Abuelas de Plaza de Mayo"- es una organización no gubernamental creada en 1977 cuyo objetivo es localizar a todos los niños desaparecidos por la última dictadura argentina y restituirlos a sus legítimas familias. CELS hace referencia al "Centro de estudios Legales y Sociales", -H.I.J.O.S -, por su parte, es la sigla que identifica a la agrupación -"Hijos e Hijas por la identidad y justicia contra el olvido y el silencio".

4. Victoria Ginzberg. (01-02- 2001). Grito contra la impunidad. Página /12, p. 11.

5. Ana Guglielmucci, La consagración de la memoria. Una etnografía acerca de la institucionalización del recuerdo sobre los crímenes del terrorismo de Estado en la Argentina, Buenos Aires, Antropofagia, 2013, p. 20.

6. Se analizó al Estado como una institución no homogénea ni monolítica, sino como un espacio de diferentes actores que se encuentran en disputa y negociaciones constantes, donde se combinan los ideales partidarios con los intereses personales.

7. Sherit Hapleitá es una institución que reúne a sobrevivientes del Holocausto. En Argentina es una de las primeras que se fundó con el fin de contener a los sobrevivientes y crear un espacio para la realización de actividades referidas a la memoria del Holocausto. También la organización en un primero momento llevó adelante trámites de indemnización de los sobrevivientes.

8. En 1991, Guido Di Tella, ex canciller del gobierno de Menem, afirmó que Argentina mantenía relaciones carnales con Estados Unidos en el marco de un encuentro con las máximas autoridades del Banco Interamericano de Desarrollo, en Washington, explicando así la política que Argentina buscaba consolidar con el país del norte.

9. El Congreso Judío Mundial es una de las organizaciones judías del mundo más importante para la comunidad. Fundado en Ginebra, Suiza en el año 1936, unificó a las comunidades y organizaciones

internacionales judías. Tiene sedes en varios países, entre ellos, Estados Unidos, Argentina, Israel, Rusia y Francia.

10. Para ampliar: http://www.argentina-rree.com/15/15-018.htm

11. Entrevista a Abraham Zylberman realizada por la autora el 10 de febrero de 2015 en la Ciudad de Buenos Aires. 
12. Beatriz Gurevich and Carlos Escudé, El genocidio frente a la historia y la naturaleza humana, Buenos Aires, Universidad Torcuato Di Tella, 1994; y por Ignacio Klich and Mario Rapoport, Discriminación y racismo en América Latina, Buenos Aires, Grupo Editor Latinoamericano, 1997. Además, se dio a conocer una selección en inglés de aquellas ponencias presentadas en el segundo volumen a través de la revista Patterns of Prejudice, Londres, 1996-1997.

13. La institución está dedicada a documentar las víctimas del Holocausto y lleva registros de los criminales de guerra nazis y sus respectivas actividades. Nació para perseguir a los nazis que habían logrado escapar luego de la Segunda Guerra Mundial. La sede central está ubicada en Los Ángeles, Estados Unidos, y lleva el nombre de Simon Wiesenthal conocido como el "caza nazis" austríaco. El Centro Simón Wiesenthal tiene sucursales en varios países del mundo: además de Argentina y Estados Unidos, tienen sede en Francia, Canadá e Israel.

14. María Laura Avignol, "El Saqueo a las víctimas del Holocausto", Clarín digital [en línea]. 21 de septiembre de 1996. Disponible en http://edant.clarin.com/diario/96/09/21/T-02201d.htm

15. Entrevista a Sergio Wiedder realizada por la autora en mayo de 2014 en la Ciudad de Buenos Aires.

16. Luis Puenzo filmó unos años después el documental "Algunos que vivieron" en un estilo televisivo-educativo, de un corte bastante tradicional, en donde enlaza fuertes fragmentos testimoniales con imágenes de archivo del Holocausto, algunas bastante conocidas como la de los enfermos de tifus que caminan desnudos, como fantasmas, pero a plena luz del día. Pero también suma imágenes de la Argentina desde el auge nacionalista de 1945 hasta los atentados a la embajada de Israel y a la AMIA.

17. Elizabeth Jelín, Los trabajos de la memoria, Madrid, Editorial Siglo XXI, 2002, p. 25.

18. E. Jelín, Los Trabajos..., p. 26.

19. Según Abraham Zylberman, “...deberían sacarse. Es una decisión comunitaria. Los pilotes lo único que hacen es marcar, como la marca de Caín, en este caso la marca de ser judío, y aparte una institución como el museo, justamente para mantener la dignidad no debería dejarse marcar como se dejaron en Polonia o en Alemania". Entrevista a Abraham Zylberman realizada por la autora el 10 de febrero de 2015 en la Ciudad de Buenos Aires.

20. E. Jelín, Los Trabajos..., p. 48.

21. "Breve reseña histórica de F.M.H”, Susana Rochwerger, p. 1. Material enviado por Rochwerger a la autora vía correo electrónico.

22. Fortunoff fue el primer proyecto que emprende la videograbación de testimonios del Holocausto realizado en el Estado de Connecticut en Estados Unidos, asociado a la Universidad de Yale. Comenzó su labor en el año 1979, a partir de la idea del psicoanalista sobreviviente del Holocausto, Dori Laub.

23. Entre los primeros entrevistados estuvieron: Eugenia Unger, Jacob Fuchs, Gilbert Hirsch, Hela Urstajn, Hanka Jacubowizc, Guita Loffler, Bele Mushkat, Charles Papernik, Victoria y Alexander Zelenay entre otros.

24. "Breve reseña histórica de F. M. H”, Susana Rochwerger, p. 1.

25. FACCMA es la Federación Argentina de Centros Comunitarios Macabeos, una organización sin fines de lucro que nuclea a 43 instituciones (centros comunitarios, entidades socio deportivas y clubes). Todas ellas conforman una extensa red nacional comunitaria. FACCMA articula y desarrolla programas culturales, educativos y deportivos en un marco judaico.

26. Acta fundacional Fundación Memoria del Holocausto (1994).

27. El monumento consta de una plataforma de hormigón revestida en acero de la cual emergen siete columnas de distintas alturas y colores con una perspectiva minimalista. Las columnas evolucionan por distintos grados de destrucción hasta llegar a las más pulidas y van desde la más oscura hasta la más clara y luminosa. Cada columna alude con diferentes colores a la guerra y a la destrucción. 
28. Sergio Widder relata un encuentro anterior, en el año 1992, cuando el Centro Simón Wiesenthal hace su acto inaugural en el Centro Cultural Recoleta e invita a sobrevivientes de la Shoá y Madres de Plaza de

Mayo. En esta ocasión, el gobierno nacional decidió no participar para no encontrarse con las Madres.

29. La ceremonia se realizó en coincidencia con el $51^{\circ}$ aniversario del levantamiento del gueto de Varsovia. Este suceso suele ser en todos los momentos y lugares la "piedra inaugural". La mayoría de los museos y monumentos se realizan en esta "fecha heroica". La elección de este día remarca un aspecto que se elige recordar del Holocausto: la resistencia y el heroísmo de quienes se enfrentaron.

30. Carlos Corach era conocido de Gilbert Lewi por pertenecer ambos a la Sociedad Hebraica y tener casa en el Country situado en Pilar, Provincia de Buenos Aires.

31. Entrevista a Graciela Jinich realizada por la autora en noviembre de 2014 en la Ciudad de Buenos Aires.

32. Años más tarde, Carlos Corach fue acusado de encubrimiento del atentado a la mutual judía por parte de la dirigencia de la DAIA. Según la entrevista realizada a Héctor Shalóm, ex director ejecutivo de la FMH, estos actos fueron un "lavado de culpa" del gobierno hacia la comunidad judía. Entrevista realizada en junio de 2016 por la autora en la Ciudad de Buenos Aires.

33. Nos referimos al fallecimiento del hijo del entonces presidente Carlos Menem en un accidente aéreo el 15 de marzo de 1995. Este hecho congeló la operación de donación del espacio, según Graciela Jinich.

34. El edificio otorgado pertenecía a la Compañía Ítalo-Argentina de Electricidad y fue diseñado por el arquitecto italiano Chiogia, con un estilo muy particular neorrenacentista florentino, trayendo reminiscencias de la arquitectura del norte de Italia, lugar de origen del autor y de la empresa. En la ciudad de Buenos Aires existen otros edificios similares como la Usina de la calle Pedro de Mendoza (hoy conocido como "Usina del Arte") en La Boca.

35. Esta práctica de recaudar fondos privados y donaciones, continúa hasta la actualidad (2016).

36. Elie Wiesel ya había visitado Argentina en agosto de 1979, un mes antes de la llegada de la Comisión Interamericana de Derechos Humanos de la OEA. Por entonces estaba a cargo del proyecto del Museo del Holocausto en Washington impulsado por el gobierno de Carter. La visita de Wiesel fue autorizada por la Junta Militar que extendió la visa de ingreso al país. En ese y otros detalles había estado trabajando el rabino norteamericano Marshall Meyer, rector del Seminario Rabínico Latinoamericano. Para ampliar, véase: "Los usos del pasado durante la última dictadura militar. El Holocausto como horizonte de identificación, distanciamiento y negociación de los actores de la comunidad judía en tiempos de régimen militar", Kahan, Schenquer (SF/ mimio).

37. Entrevista a Abraham Zylberman realizada por la autora el 10 de febrero de 2015 en la Ciudad de Buenos Aires.

38. 30 de Septiembre de 1996 [en línea]. Disponible en http://edant.clarin.com/diario/96/09/30/ E-03601d.htm (último ingreso 01/10/16).

\section{RESÚMENES}

En el presente artículo se analiza el contexto de creación de la Fundación Memoria del Holocausto, organización responsable del Museo del Holocausto de Buenos Aires. Este proceso se extendió entre fines de los años ochenta y mediados de los años noventa del siglo XX, años en los 
que un grupo de emprendedores de la memoria buscó posicionar su memoria en el ámbito público. En este marco, el trabajo se propone indagar cuáles fueron los sucesos y actores que posibilitaron la aparición de un sitio que puso en escena una memoria lejana en tiempo y en espacio en la Ciudad de Buenos Aires.

No presente artigo, analisa-se o contexto da criação da "Fundação Memória do Holocausto", organização responsável pelo Museu do Holocausto, de Buenos Aires. Este processo estendeu-se entre o final dos anos oitenta e meados dos anos noventa do século XX, anos em que um grupo de empreendedores da memória procurou posicionar a sua memória na esfera pública. Neste sentido, o artigo propõe-se indagar quais foram os eventos e atores que possibilitaram a aparição de um sítio que organizou uma memória distante no tempo e no espaço na Cidade de Buenos Aires.

This article studies the context of creation of the Memory of the Holocaust Foundation. This organization was responsible for the Holocaust Museum of Buenos Aires. The process took place between the late eighties and mid-nineties of the twentieth century, when a group of memory entrepreneurs sought to position their memory in the public sphere. The article focused on the events and actors that made possible the appearance in the City of Buenos Aires of a specific place destined to stage a distant memory in time and space.

\section{ÍNDICE}

Keywords: Holocaust, memory, museum

Palavras-chave: Holocausto, memória, museu

Palabras claves: Holocausto, memoria, museo

\section{AUTOR}

\section{WANDA WECHSLER}

Universidad Nacional Arturo Jauretche, Docente e investigadora de la Universidad Nacional Arturo Jauretche. Magister en Investigación Histórica (UdeSA)- Historiadora (UBA). Doctorando en Historia (UdeSA). Integrante investigadora del "Núcleo de Estudios Judíos" y del Grupo "Lugares, Marcas y Territorios de la memoria" (IDES).

wandaprofesora[at]gmail.com 